\title{
Can neonates born at 34 weeks be classified as late preterm?
}

\author{
Małgorzata Baumert ${ }^{1}$, Piotr Surmiak ${ }^{1}$, Zofia Walencka ${ }^{1}$, Ewa Mrowiec ${ }^{1}$, Patrycja Sodowska ${ }^{2}$ \\ ${ }^{1}$ Department of Neonatology, School of Medicine in Katowice, Medical University of Silesia in Katowice, Poland \\ ${ }^{2}$ Centrum Medyczne Krzysztof Sodowski, Katowice, Poland
}

\begin{abstract}
Objectives: In recent years, much attention has been given to infants born prematurely, at $340 / 7$ to 36 6/7 weeks of gestation (WG), which have been classified as 'late preterm'. Neonates from that subgroup are less physiologically and metabolically mature than term infants. The aim of the study was to determine whether infants born at 34 WG can be classified as 'late preterm' or 'preterm' newborns.

Material and methods: A total of 141 newborns were included in the study: 25 born $\leq 33 W G, 53$ late-preterm newborns, and 63 term infants. Cord-blood neutrophil gelatinase-associated lipocalin (NGAL) and creatinine concentrations were measured in all newborns. Also, the incidence of clinical complications in the early adaptive period during hospitalization was evaluated.

Results: Higher NGAL concentration was noted among preterm newborns as compared to late-preterm neonates $(p<0.05)$, and term newborns ( $p<0.05$ ), especially in children born at 34WG as compared to 35WG ( $p<0.001$ ). However, no differences in NGAL concentration were found between neonates born at 35WG and 36WG, as well as children born at 36WG and term infants. A relationship between umbilical NGAL levels and gestational age was observed. Additionally, a statistically significant difference was found in the incidence of respiratory distress syndrome $(p<0.05)$ and infections $(p<0.05)$ among neonates born at 34WG as compared to 35WG.

Conclusions: Late preterm neonates should be defined as 'preterm' between 35 0/7 and 36 6/7 WG. Infants born at 34 WG should be included in the preterm group.
\end{abstract}

Key words: late preterm infant, NGAL, clinical complication

\section{INTRODUCTION}

Definitions of 'preterm','term' and 'post-term' birth have been specified by the American Academy of Pediatrics, American College of Obstetricians and Gynecologists, and the World Health Organization [1, 2]. Accordingly, preterm birth occurs $\leq$ the last day of the $37^{\text {th }}$ week (day 259), whereas term birth on the first day of the $38^{\text {th }}$ week. The 2005 National Institutes of Health workshop recommended for infants born at 34 0/7 to 36 6/7 weeks of gestation (WG) after the onset of the mother's last menstrual period, to be referred to as 'late preterm' [3].

In recent years, much attention has been given to this subgroup of newborns. Late preterm infants are less physiologically and metabolically developed than term newborns and thus present with a significantly greater number of medical complications as compared to full-term infants [4-6].

The aim of the study was to determine whether infants born at 34WG can be classified as 'late preterm' or 'preterm' newborns.

\section{MATERIAL AND METHODS}

A total of 141 neonates ( 25 born at $\leq 33$ WG, 53 between $340 / 7$ and 36 6/7 WG, and 63 term infants) were enrolled in the study between January and April 2013. The exclusion criteria were as follows: major congenital malformations, and maternal kidney and liver diseases and diabetes.

APGAR at 5 min., incidence of respiratory distress syndrome, prevalence of infection and cord-blood neutrophil 
Table 1. General well-being assessment according to the Apgar score in the $5^{\text {th }}$ minute of life, prevalence of Infant Respiratory Distress Syndrome (IRDS), infection, concentration of neutrophil gelatinase-associated lipocalin (NGAL) as well as creatinine in the analyzed groups of neonates

\begin{tabular}{|c|c|c|c|c|c|}
\hline Study group & $\begin{array}{l}<33 \text { WG } \\
(n=25)\end{array}$ & $\begin{array}{c}34 \text { WG } \\
(n=21)\end{array}$ & $\begin{array}{l}35 \text { WG } \\
(n=14)\end{array}$ & $\begin{array}{l}36 \text { WG } \\
(n=18)\end{array}$ & $\begin{array}{l}>37 \text { WG } \\
(n=63)\end{array}$ \\
\hline Apgar score $5^{\text {th }} \min [p t s]^{*}$ & $4[0-6]$ & $5[1-6]$ & $6[4-8]$ & $7[5-10]$ & $9[6-10]$ \\
\hline RDS (\%) & 25.3 & 18.3 & 12.0 & 9.5 & 2.7 \\
\hline Congenital infection (\%) & 15.0 & 11.4 & 7.6 & 7.8 & 4.5 \\
\hline NGAL level $[\mathrm{ng} / \mathrm{mL}]^{* *}$ & $\begin{array}{c}127.4 \\
{[33.78-201.9]}\end{array}$ & $\begin{array}{c}116.9 \\
{[53.8-148.1]}\end{array}$ & $\begin{array}{c}59.4 \\
{[36.3-97.7]}\end{array}$ & $\begin{array}{c}23.7 \\
{[21.9-25.2]}\end{array}$ & $\begin{array}{c}23.4 \\
{[21.7-25.2]}\end{array}$ \\
\hline Creatinine level $[\mathrm{mg} / \mathrm{dL}]^{* *}$ & $\begin{array}{c}0.9 \\
{[0.8-1.0]}\end{array}$ & $\begin{array}{c}0.8 \\
{[0.7-0.9]}\end{array}$ & $\begin{array}{c}0.8 \\
{[0.7-0.9]}\end{array}$ & $\begin{array}{c}0.7 \\
{[0.6-0.8]}\end{array}$ & $\begin{array}{c}0.6 \\
{[0.5-0.8]}\end{array}$ \\
\hline
\end{tabular}

*Result shown as median and (minimum and maximum values)

WG — weeks of gestation; RDS — respiratory distress syndrome; NGAL — neutrophil gelatinase-associated lipocalin

gelatinase-associated lipocalin (NGAL) and creatinine levels were compared. Infant respiratory distress syndrome was diagnosed if expiratory grunting, nasal flaring, and chest wall retractions lasting $>2$ hours were observed. Newborns requiring reactive oxygen therapy, respiratory support with the use of nCPAP (nasal Continuous Positive Airway Pressure), and/or mechanical ventilation (MV) were also included in the study group.

Infection was diagnosed upon clinical examination (including feeding difficulties, jaundice and increased irritability or lethargy) and laboratory tests - white blood cell count, C-reactive protein (CRP) tests, obtained thrice at 12-hour intervals, blood cultures and antibiotic treatment. Blood samples for NGAL concentration were centrifuged at $2500 \mathrm{rpm}$ for $10 \mathrm{~min}$. Serum was stored at $-70^{\circ} \mathrm{C}$ until assayed. NGAL concentrations were measured using a sandwich enzyme immunoassay for the quantitative measurement of human lipocalin-2 (BioVendor - Laboratorni medicina a.s., Brno, Czech Republic).

Local Ethics Committee approved of the study and written parental consent was obtained. Statistical analysis was performed using STATISTICA 10 (Statsoft Polska Inc.). Normal distribution was tested using the Shapiro-Wilk test, while statistical significance was assessed using the Mann-Whitney $U$ test for two groups and the Kruskal-Wallis test for all neonatal groups. Quantitative variables are presented as median, confidence interval or minimum and maximum values, while qualitative variables are presented as percentages. The $p$-value of $<0.05$ was considered as statistically significant.

\section{RESULTS}

No significant differences were observed as far as neonatal gender was concerned. Respiratory distress syndrome was recognized markedly more often in children born at 34 WG as compared to 35 WG $(18.3 \%$ vs. $12.0 \%$; $p<0.05)$, and 36 WG $(9.5 \% ; p<0.05)$. Similarly, the prevalence of infection was higher at 34 WG as compared to 36 WG (15\%

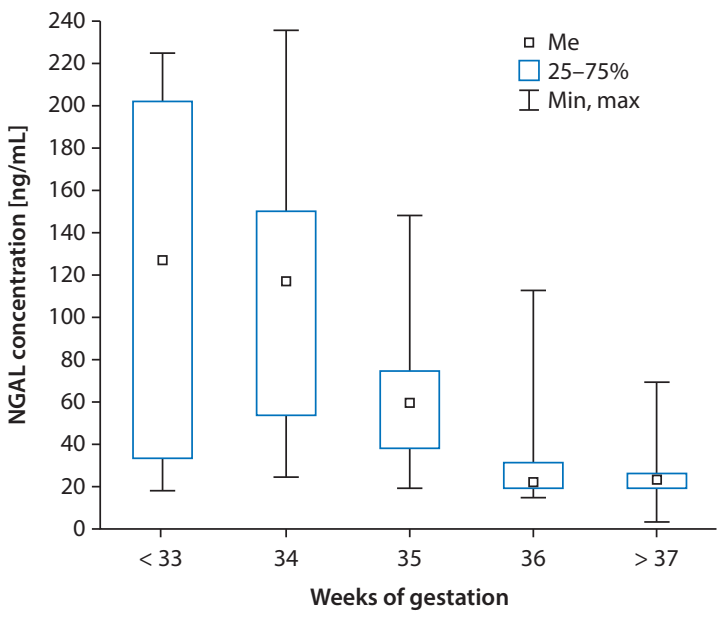

Figure 1. Concentration of neutrophil gelatinase-associated lipocalin (NGAL) in the various groups of neonates.

Results shown as median, 95\% confidence interval for median, and maximum and minimum values

vs. $7.6 \%, \mathrm{p}=0.05)$, and term newborns $(2.7 \% ; \mathrm{p}<0.05)$. Higher Apgar scores correlated directly with higher gestational age (Tab. 1).

Significant differences in NGAL concentrations were detected between neonates born at 34 WG $(116.9 \mathrm{ng} / \mathrm{mL}$; $95 \% \mathrm{Cl} 53.8,148.1 \mathrm{ng} / \mathrm{mL})$ and $35 \mathrm{WG}(59.4 \mathrm{ng} / \mathrm{mL} ; 95 \% \mathrm{Cl}$ $36.3,97.7 \mathrm{ng} / \mathrm{mL} ; \mathrm{p}=0.03)$, as well as $36 \mathrm{WG}(23.7 \mathrm{ng} / \mathrm{mL}$; $95 \% \mathrm{Cl} 21.9,25.2 \mathrm{ng} / \mathrm{mL} ; \mathrm{p}<0.001$ ) (Fig. 1). There were no differences in NGAL concentrations between infants born at < 33 WG $(127.4 \mathrm{ng} / \mathrm{mL} ; 95 \% \mathrm{Cl} 33.78,201.9 \mathrm{ng} / \mathrm{mL})$ and 34 WG (116.9 ng/mL; $95 \% \mathrm{Cl} 53.8,148.1, \mathrm{p}=0.54)$. Also, no differences were found in creatinine concentrations between either of the investigated groups of children.

\section{DISCUSSION}

Our study revealed that neonates born at 34 WG were more immature than those born $\geq 35$ WG but yet were still 
included in the late preterm group, earlier also known as neonates born near term. It is connected with major complications in the postnatal period, which arise mainly due to the immaturity of vital organs, with respiratory distress syndrome being the dominant problem.

In our material, respiratory distress syndrome requiring nCPAP or mechanical ventilation was observed more often in children born at 34 WG as compared to neonates born at 35 WG. No such correlation was found between children born at 35 and 36 WG. The reason for this syndrome may be due to insufficient presence of surfactant $[7,8]$. Similar views were expressed also by other authors [9].

Our study also found that higher incidence of intrauterine infections, occurring during the early neonatal period, in children born at 34 WG as compared to those born at 36 WG, caused more serious complications during that period. In contrast, no such difference was observed between infants born at 35 and 36 WG. This may provide supporting evidence to confirm immune immaturity in that group of neonates. However, it is a well-known fact that innate immune response of preterm infants is reduced in its cellular responses to infection. Soluble proteins and peptides have the ability to opsonize pathogens and, in that way, directly kill them through their antimicrobial properties, thus limiting production of soluble factors, such as immunoglobulins (lg). Low lgG levels result in a lack of opsonization, leading to deficiencies in phagocytosis [10]. Preterm infants have a reduced pool of neutrophils and monocytes, and their precursors (phagocytic cells), due to the diminished granulocyte colony-stimulating factor (G-CSF) and granulocyte-macrophage colony-stimulating factor (GM-CSF) levels [9]. Although the monocytes of preterm infants have reduced cytokine production, there is similar efficiency in phagocytosis and intracellular killing of pathogens as that of term neonates [11, 12]. Moreover, preterm neonates are deficient in the production of $\mathrm{C} 1, \mathrm{C} 4$ (classical pathway) and factor B (alternative pathway) as compared to term neonates [13].

Animal studies have demonstrated that NGAL plays a critical role in kidney development during the conversion of progenitor cells into epithelia and tubules, and its expression is suppressed once kidney development is complete [14]. Lavery et al., hypothesized that NGAL would be detectable in urine of very low birth weight (VLBW) infants with ongoing nephrogenesis [15]. Several authors have reported NGAL to be inversely proportional to birth weight and gestational age $[16,17]$. Nephrogenesis begins at 5 and is completed by 36 WG. Our study found NGAL concentration in neonates born at 34 WG to be significantly elevated as compared to infants born at 35 WG. However, there was no difference in infants born $<33$ WG.

Also, no significant differences were observed in creatinine concentrations between infants born $<33$ WG and near-term neonates. Creatinine concentration, however, is unreliable due to the fact that serum creatinine levels in newborns in their first few days of life reflect maternal renal function due to placental transfer [17].

It seems safe to conclude that neonates born at 34 WG should be classified as preterm rather than near-term infants.

\section{REFERENCES}

1. American Academy of Pediatrics and American College of Obstetricians and Gynecologists 2005. Guidelines of Perinatal Care. 5th Ed. American Academy of Pediatrics. Elk Grove Village. 2005, 211-220.

2. World Health Organization (WHO) International Statistical Classification of Diseases and Related Health Problems, Geneva 1992, rev. 10, vol. 1 and 2.

3. Raju TN, Higgins RD, Stark AR, [et al.]. Optimizing care and outcome for late-preterm (near-term) infants: a summary of the workshop sponsored by the National Institute of Child Health and Human Development. Pediatrics. 2006, 118, 1207-1214.

4. Baumert M, Agnieszka L, Krzych L, [et al.]. Late preterm infants — complications during the early period of adaptation. Ginekol Pol. 2011, 82, 119-125.

5. Medoff Cooper B, Holditch-Davis D, Verklan MT, [et al.]. Newborn clinical outcomes of the AWHONN late preterm infant research-based practice project. JOGNN. 2012, 41, 774-785.

6. Baumert M, Sypniewska K, Surmiak P. Późny wcześniak. Ann Acad Med Siles. 2012, 66, 24-28.

7. Jobe AH, Ikegami M. Biology of surfactant. Clin Perinatol. 2001, 28, 655-669.

8. Jobe A. The role of surfactant in neonatal adaptation. Semin Perinatol. $1988,12,113-123$.

9. Mateus J, Fox K, Jain S, [et al.]. Preterm premature rupture of membranes: clinical outcomes of late-preterm infants. Clin Pediatr (Phil). 2010, $49,60-65$.

10. Melville JM, Moss TJ. The immune consequences of preterm birth. Front Neurosci. 2013, 7, 79.

11. Carr R, Modi N. Haemopoietic colony stimulating factors for preterm neonates. Arch Dis Child Fetal Neonatal Ed. 1997, 76, F128-F133.

12. Currie AJ, Curtis S, StrunkT, [et al.]. Preterm infants have deficient monocyte and lymphocyte cytokine responses to group B streptococcus. Infect Immun. 2011, 79, 1588-1596.

13. McGreal EP, Hearne K, Spiller OB. Off to a slow start: under-development of the complement system in term newborns is more substantial following premature birth. Immunobiology. 2012, 217, 176-186.

14. Devarajan P. Update on mechanisms of ischemic acute kidney injury. J Am Soc Nephrol. 2006, 17, 1503-1520.

15. Lavery AP, Meinzen-Derr JK, Anderson E, [et al.]. Urinary NGAL in premature infants. Pediatr Res. 2008, 64, 423-428.

16. Huynh TK, Bateman DA, Parravicini E, [et al.]. Reference values of urinary neutrophil gelatinase-associated lipocalin in very low birth weight infants. Pediatr Res. 2009, 66, 528-532.

17. Guignard JP, Drukker A. Why do newborn infants have a high plasma creatinine? Pediatrics. 1999, 103, e49. 